der Zersetzung unterliegenden Bronchialinbaltes absatzweise, indem nur stärkere Hustenimpulse demselben neben dem Knochen einen Weg zu bahnen vermochte; in der Zwischenzeit erschien dann wieder das gutartige Product des begleitenden Bronchialcatarrbes in den freien. Lungentheilen. In den letzten Tagen vor dem Tode fehlte die nöthige Kraft zur Forcirung jenes Durchganges ganz und gar, daher auch die strotzende Ueberfüllung der Bronchien in der Leiche.

In therapeutischer Hinsicht würde bei gesicherter Diagnose die Frage von der Zweckmässigkeit einer Tracheotomie in den Vordergrund treten. Ohne die vielen Discussionen über den allgemeinen Werth der genannten Operation behufs Entfernung fremder Körper aus den Luftwegen vermehren zu wollen, bemerken wir nur, dass bei Einkeilung des Körpers in einem Bronchialaste, wie im vorbeschriebenen Falle an eine instrumentale Extraction wohl nicht $2 u$ denken, mithin der Nutzen der Operation sich darauf beschränken würde, bei eventueller spontaner Loslösung des Eindringlings einen leichten und gefahrlosen Eliminationsweg für denselben offen und bereit zu haben. Bei der Gefährlichkeit der 0peration selbst aber dürfte es gerathen sein, dieselbe erst dann auszuführen, wenn jene erwartete Lockerung und Aufwärtsbewegung des Körpers wirklich eingetreten ist, was sich meist durch unzweideutige, sowobl subjective wie objective Zeichen kundgiebt. Ohne eine solche durch erreichbare Nähe des Körpers und drohende Zufalle gegebene Aufforderung wird man um so weniger jenen lebensgefährlichen Eingriff von zweifelhaftem Erfolge wagen, da es nicht an Erfabrungen fehlt, wo solche von aussen hineingerathene Bronchialpfröpfe nach anfänglich beunruhigenden Erscheinungen allmälig an schädlicher Bedeutung verloren, indem sie von einer sich bildenden Aussackung des Bronchialastes aufgenommen und des Letzteren Lumen dadurch wieder für den Luftstrom frei wurde. Vergl. einen solchen auf der $\mathbf{O p}_{\mathrm{p}}$ polzer'schen Klinik beobachteten Fall in der Wiener Med. Wochenschrift 1853, No. 13. Bei Unterlassung eines operativen Eingriffes wird im Uebrigen die Bebandlung sich nach der. Gestaltung der Krankheit richten, namentlich eine durch den Reiz des fremden Körpers hervorgerufene Bronchopneumonie mit denselben Mitteln bekämpft werden müssen, wie eine idiopathische Lungenentzündung.

5.

\title{
Zur chemischen Natur der wahren oder chondrogenen Knorpel und der Knochen oder collagenen Knorpel.
}

Von C. Trommer in Eldena.

Bekanntlich hat Dr. Alexander Friedleben*) die interessante Beobachlung gemacht, dass, wenn wahre oder chondrogene Knorpel eine Zeitlang mit ver-

*) Man vergleiche hierüber die Zeitschrift für wissenschaftliche Zoologie von v. Siebold und Kölliker Bd.X. Heft 1. 1859. S. 20. 
dünnter Salzsäure behandelt werden, und $z$ war in uhnlicher Weise wie man mit den Knochen verfährt, wenn deren Knorpel frei von ihren erdigen Bestandtheilen dargestellt werden sollen, - als dann die wahren Knorpel beim Kochen mit Wasser nicht mehr Chondrinreactionen zeigen, sondern deren Auflösung ganz wie die Auflösung des Knochenknorpels reagirt, und die wahren Knorpel eine collagene Natur angenommen haben. Ich kann die von Friedleben gemachte Beobachtung nur bestätigen, und füge noch hinzu, dass nicht allein Salzsăure, sondern auch verdünnte'Schwefelsäure und Phosphorsäure die Umwandlung des chondrogenen Knorpels in einen collagenen hervorbringen.

Friedleben zieht hieraus den Schluss, dass der Knochenknorpel ursprünglich auch ein chondrogener, mindestens kein collagener sei; denn durch die Behandlung der Knochen mit Salzsäure werde deren Knorpel erst in einen collagenen umgeändert. Aus den Knochen an und für sich könne man, so meint wenigstens Friedleben, durch Kochen mit Wasser den Knorpel nicht auszieben, und die collagenen Reactionen, die dennoch erfolgen, wären auf Rechnung des massenhaften Bindegewebes der Gefässe und der Havers'schen Kanäle der Knochen zu bringen. In wie weit diese letztere Ansicht oder Behauptung richtig ist, wollen wir einstweilen dahin gestellt sein lassen. Wir werden später noch einmal hierauf zurückkommen. Was bingegen obigen von Friedleben ausgesprochenen Schluss anbetrifft, so können wir die Richtigkeit desselben durchaus nicht theilen. Friedleben hat dabei eine Erscheinung ganz übersehen; dieselbe besteht nämlich darin, dass genannte Säuren und namentlich die Salzsäure den wahren Knorpel bei der gewöhnlichen Temperatur ganz unverändert lassen und denselben nicht in einen collagenen umwandeln. Wenn man daher dergleichen Knorpel auch längere Zeit hindurch (mehrere Tage) bei gewöhnlicher Temperatur mit verdünnter Salzsäure in Berübrung lässt, und vor der Behandlung desselben mit kochendem Wasser nur dafür sorgt, dass jede Spur der Säure entfernt wird, so zeigt alsdann die Auflösung des Knorpels nur chondrogene Reactionen.

Dje vollstăndige Entsäuerung eines solchen Knorpels ist indessen nicht leicht. Mit Wasser allein erreicht man diesen Zweck noch njcht, selbst wenn man melırere Tage hindurch mit dem Prozess des Auswaschens fortfährt. Bleibt aber selbst die-geringste Menge der Säure zurück, so sind in der nachherigen Lösung des Knorpels alle chondrogenen Reactionen verscbwunden. - Um daber zum Ziele zu kommen, muss man den möglichst mit Wasser ausgewaschenen zerkleinerten Knorpel zuletzt noch mit einer sehr verdünnten Aetzammoniaklösung so lange behandeln, bis jede saure Reaction verschwunden ist. -. Wird aber der, vermittelst Salzsäure von seinen Erden befreite Knochenknorpel unter den angegebenen Vorsichtsmaassregeln auch vollständig entsäuert, so giebt dessen nachherige Auflösung nichtsdestoweniger collagene Reactionen. Ausserdem halten wir aber auch jene von Friedleben ausgesprochene Behauptung, als sei der Knochenknorpel durch blosses Kochen mit Wasser von seinen Erden durchaus nicht trennbar, für unhaltbar. Möglichst fein gepulverte Knochen hinterlassen nach fortwäbrendem Kochen mit Wasser, nacbdem dieselhen jmmer wieder von Nevem zerkleinert oder zerrieben werden, endlicb nur die erdigen Bestandtheile. Es bedarf bierzu keineswegs 
eines Papinschen Digestor, sondern man kann dies vollständig durch einen Apparat erreichen, wie derselbe von Mitscherlich in dessen Lehrbuche der Chemie 1844, S. 221 beschrieben und abgebildet ist. Dieser Apparat empfiehlt sich überhaupt für alle dergleichen Fälle, wo man Substanzen längere Zeit bindurch mit einer kochenden Flüssigkeit behandeln will.

Schliesslich sei es mir gestattet, hier noch einige Bemerkungen über die Reactionen des Chondrins und des Knochenleims za machen.

Eine Chondrinlösung giebt beim Zusatz von Essigsäure, Weinstein-

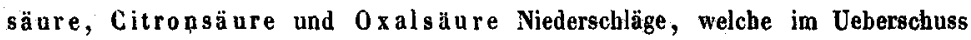
dieser Säuren unlöslich sind. Dasselbe gilt von einer Auflösung des Alauns, des schwefelsauren Kupferoxyds und des Eisenchlorids. Mineralische Sätren, wie Schwefelsäure, Salpetersäure, Phosphorsäure und Salzsäure einer Chondrinlösung binzugesetzt, bewirken zwar anfänglich auch einen Niederschlag, derselbe ist aber im Ueberschuss genannter Săuren wiederum löslich.

Eine Auflösung des Knochenknorpels zeigt hingegen keine dieser erwähnten Erscheinungen. Wohl aber wird hier sogleich ein Niederschlag durch Gerbsäure hervorgebracht. Eine Chondrinlösung trübt sich zwar beim Zusatz von Gerbsäure auch in etwas, indessen ein eigentlicher Niederschlag wird dadurch nicht hervorgebracht. Es beschränkt sich hier das Ganze auf eine blosse Opalisirung der Flüssigkeit. - Ich bin der Ansicht, dass diese Erscheinung vom anhängenden oder heigemengten Glutin herrührt, da bekanntlich die wahren Knorpel ebenfalls nicht frei von Bindegewebe sind, und dass ferner reines Chondrin auf den Zusatz von Gerbsäure gar nicht reagirt.

Was die Beschaffenheit der wahren knorpel anbetriff, wenn dieselben z. B. in gewissen Krankheitsfällen, oder bei anderen Gelegenheiten verknöchern, so bin ich gegenwärtig leider noch nicht im Stande, ein Urtheil hierüber abzugeben. $Z u$ seiner Zeit soll aber auch dies geschehen.

D $r u c k f$ e 1 e r.

S, 163 Z. 9 v. oben: Anamnese statt Annahme

S. 150 Z. 4 v. unten: Die Eiterzelle statt Eine Eiterzelle

S. 117 Z. 9 v. unten: exspiratorische statt aspiratorische 